\title{
POLÍTICAS EDUCACIONAIS, PARTICIPAÇÃO E GESTÃO DEMOCRÁTICA DA ESCOLA NA CONTEMPORANEIDADE BRASILEIRA
}

\begin{abstract}
Maria
RESUMO: Este artigo tem como objetivo analisar os condicionantes sócio-históricos
das políticas educacionais no Brasil, o entendimento da participação como um dos canais do processo democrático e a gestão democrática da escola a partir da década de 1990. Utilizamos como caminho metodológico o materialismo histórico-dialético com o intuito recorrente de problematizar os elementos desveladores do objeto organizados em três eixos, a saber, a) políticas educacionais no Brasil: consensualidade e naturalização; b) participação e democracia induzidas na e para a escola no Brasil; e c) gestão democrática: olhares e leituras de mundo. O estudo evidenciou a necessidade de processos emancipatórios e políticos da escola no Brasil não condicionados por sua redução à lógica do mercado, mas orientados pelo processo de construção permanente da consciência coletiva e emancipação na razão libertadora do homem. Palavras-chave: políticas educacionais, gestão democrática, participação

\section{EDUCATIONAL POLICIES, PARTICIPATION AND DEMOCRATIC MANAGEMENT OF THE BRAZILIAN SCHOOL IN CONTEMPORANEITY}

ABSTRACT: This article aims to analyze the socio-historical conditions of educational policies in Brazil, the understanding of participation as one of the channels of the democratic process and democratic administration of the school since the 1990s. We used as a methodological path historical and dialectical materialism in order to question the applicant unveiled elements of the object held in three axes, namely a) educational policies in Brazil: consensuality and naturalization; b) participation and democracy in the induced and the school in Brazil; and c) democratic management: views and readings of the world. The study showed the need for emancipatory and political processes of the school in Brazil is not conditioned by its reduction to the market logic, but on the process of ongoing construction of collective consciousness and emancipation in the ratio of liberation of man.

Keywords: educational policies, democratic management, participation
\end{abstract}

Paulo Gomes Lima * Alice de Miranda Aranda** Antonio Bosco de Lima*** 
Paulo Gomes Lima | Maria Alice de Miranda Aranda Antonio Bosco de Lima

\section{INTRODUÇÃO}

As políticas educacionais no Brasil, a indução à participação e a gestão democrática a partir da década de 1990 foram objetos arquitetados como recorrências necessárias à transformação da escola, conforme a tipologia de homem a ser formado diante do processo de reestruturação produtiva do mercado internacional entre a consensualidade e a naturalização de interesses particularistas.

A consensualidade e naturalização a essa direção para os arranjos sócio-históricos e educacionais manifestada por diferentes segmentos naturalizou tal ideário como única alternativa possível ao processo de crescimento econômico mundial sem maiores resistências, o que numa sociedade marcada pela expropriação do trabalho e divisão social de classes haveria de ser, no mínimo, considerado como ato de suspeição e estranheza, mas, ao contrário, sob a tutela da solidarização ao ideário do sociometabolismo do capital, houve uma aquiescência por parte dos Estados, inclusive do Estado Brasileiro, no sentido de se provocar a reforma do Estado como elemento desencadeador de medidas e políticas educacionais promotoras do controle social e contenção de movimentos sociais que destoassem de seus pressupostos.

Há um forte apelo ao esforço encampado pelo Estado em reunir intelectuais, a classe política e o empresariado na elaboração das políticas públicas para a educação, na apresentação de uma escola pública que ratificasse os pressupostos delineados pelos organismos multilaterais, o que em maior ou menor grau tem se intensificado na roda de discussão de toda a sociedade e, particularmente, na adesão de um bom número de acadêmicos, cooptados pelo convencimento da falta de alternativa no contexto global.

A escola, considerada simplesmente como espaço executor das políticas educacionais, evidenciou a convocação comunitária como moeda de troca na promoção da pretensa gestão democrática consentida por meio de canais de participação, desde que observados os limites impostos no processo de deliberação social nos distintos instrumentos: conselhos de escola, gestão democrática, projeto político-pedagógico, associação de pais e mestres, dentre outros.

Por conta do esvaziamento dos movimentos populares e sociais, a gestão democrática, entre a pretensão de emancipação como projeto inicial e a conservação do espírito autocrático metamorfoseado de democrático, teve como elemento prevalecente o segundo eixo. Esse quadro marcado pelas relações de alienação e introjeção da verdade do mercado como única alternativa aos processos de crise mundial contribuiu para a construção de uma ideia fragilizada de gestão democrática, de tal forma que os canais de sua legitimação passaram a ser considerados fim em si mesmos, descaracterizando-se a sua finalidade em nível de emancipação social, como observaremos em uma enquete realizada numa pequena cidade de Minas Gerais, identificada neste estudo.

A partir do encadeamento descrito, organizamos este trabalho em três 


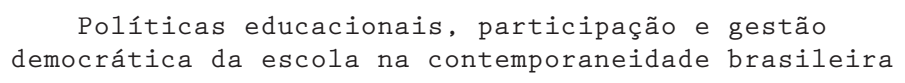

eixos, de maneira a problematizar os condicionantes sócio-históricos de sua constituição, o que é possível por meio do materialismo histórico-dialético que, em uma perspectiva recorrente, tornou-se elemento indispensável para o desvelamento do objeto. Inicialmente, analisamos as políticas educacionais no Brasil e o processo de consensualidade e naturalização dos pressupostos do mercado capitalista, destacando-se os mecanismos indutores de sua adesão ao ideário neoliberal. Em seguida, discriminamos a tipologia de participação e democracia consentidas à escola no Brasil em contraposição à efetividade do processo de consciência coletiva e finalmente, no terceiro eixo, por meio de uma pontuada enquete sobre a gestão democrática, discutimos por meio de devolutivas de gestores os olhares e leituras de mundo sobre o plano da efetividade, da necessidade e da efetividade.

\section{POLÍTICAS EDUCACIONAIS NO BRASIL: CONSENSUALIDADE E NATURALIZAÇÃO}

O quadro de dimensão democrática e luta popular à luz do neoliberalismo oculta, por meio de suas premissas, pontos de inflexão de seu ideário, que são defendidos através de estratagemas, fazendo valer políticas sociais muito mais voltadas para o populismo do que às demandas populares, muito mais a ratificação do sistema capitalista do que a projeção de sua superação. O espaço amplo de liberdade é reduzido às conveniências da lógica do mercado internacional, e as políticas educacionais, contingenciadas à conservação ou consecução dos parâmetros que deem sustentação para a sua teoria social. As políticas educacionais no Brasil não estiveram e não estão imunes à orquestração da ordem capitalista mundial; como observa Sanfelice (2002, p.xvi-xvii):

Já que a escola pública, em seus diferentes níveis e modalidades, tem sido necessária ao capitalismo, é melhor incluí-la na orquestra sob a regência de uma mesma batuta, do que viabilizar que ela desafine. As economias locais, os Estados nacionais [...] não importa mais a nomenclatura que se use com suas respectivas políticas educacionais para os seus sistemas públicos de ensino, vão gradativamente sendo obrigados, mas também com o consentimento de representantes locais, a dançarem uma única música [...] Internamente as situações vão se repetindo em nível estadual [...]. Garantidos os interesses privatistas, a escola pública que vai sobrevivendo por necessidade do capital [...] tem que ser afinada pela mesma regência para que, apesar dos resultados adversos, a vitória final seja do contendor por enquanto mais forte: o capital.

A consensualidade quanto ao ideário neoliberal nas políticas educacionais no Brasil, cujas premissas centrais eram correspondentes aos pressupostos privatistas do empresariado e da classe hegemônica, não tardou a ser materializada na elaboração da "Constituição Federal de 1988, da Lei de Diretrizes e Bases da Educação Nacional 9.394/96, da Lei n. 9.424/96, da Emenda Constitucional n.14/96 [...]", dentre outros documentos (SILVA, 2002, p.4). Vale destacar que tal quadro não se compusera de repente, uma vez que a intervenção sistemática das agências de financiamentos internacionais, sob a consensualidade do governo brasileiro, 
dispunha sua macropolítica, redirecionando as políticas públicas (sociais), no caso de nosso estudo, das políticas educacionais, ao modelo de desenvolvimento econômico - nesse caso, de uma educação determinada segundo a classe social a que se destinara.

Por exemplo, a partir da década de 1970, há uma preocupação com a reestruturação produtiva em nível internacional. Por isso, muitos eventos começam a se projetar em sentido universalista, no refrão das recorrências do processo de globalização. Havia que se justificar o processo de neocolonização do capital, cujo processo de naturalização precisava ser legitimado. Isso vai se dar inicialmente com o PROMEDLAC (Projeto Principal de Educação para a América Latina e Caribe), assinado em 1979 pelos países da região, passando a ser chamado de PRELAC (Projeto Regional de Educação para a América Latina e Caribe).

Esse evento tinha como meta estabelecer objetivos, projetos e programas que favorecessem o avanço educacional e diminuição das desigualdades. A educação para todos já era elemento constitutivo de sua agenda. Tais ideais perpassaram a década de 1980 criando eco na Convenção das Nações Unidas sobre os direitos da criança (1989). Outros eventos internacionais que se seguiram foram a Conferência Mundial sobre Educação para Todos (1990), Encontro Mundial de Cúpula pela Criança (1990), Encontro de Nova Delhi (1993) e a Reunião de Kingston na Jamaica em 1996, em que o Brasil fora solidário assignante.

Nesses eventos internacionais unanimemente eram defendidos a filosofia de atenção integral à criança, o encampamento da educação como responsabilidade de "todos", a Reunião de Kingston como projeto de melhoria da educação mundial, destacando-se o esforço pela solidariedade universal. Enfim, tais eventos em maior ou menor grau, financiados por organismos multilaterais, difundiam o mesmo foco: elaboração de políticas educacionais, focalização assistencialista, erradicação da pobreza, acesso à universalização dos códigos da modernidade (leiase "poder de compra de tecnologias"), racionalização dos gastos.

Esses pontos foram observados na agenda das políticas educacionais no Brasil a partir da Constituição Federal de 1988 na projeção de se "eliminar o analfabetismo e universalizar o ensino fundamental", assegurar o acesso e permanência da criança na escola e favorecer uma qualidade sustentável de educação (o que seria estendido em nível conceitual sobre educação básica: educação infantil, ensino fundamental e ensino médio). Na LDBEN 9394/1996, tida como a mais democrática das legislações educacionais no Brasil, o estreitamento legal aproxima as necessidades educacionais debatidas por meio de políticas pertinentes às políticas e estratégias do Banco Mundial. Por isso, Freitas (2004, p. 8) destaca que

Estados como o Brasil, sob o efeito das mudanças nas relações internacionais (a chamada globalização) foram colocados na contingência de induzir soluções pré- concebidas além fronteira em seus assuntos locais, sob o controle de organismos internacionais que passaram a ocupar o papel central na aplicação da política internacional dos países ricos, em associação com o direcionamento dos fluxos de capitais. 
A naturalização das medidas externas dos organismos multilaterais tem sido trabalhada como receita às necessidades locais do Estado brasileiro, uma vez que educação e políticas sociais assistencialistas são colocadas no mesmo patamar de equivalência. Logo, as políticas educacionais, a partir da reforma do Estado de FHC, seriam confundidas ou convenientemente orientadas como políticas sociais, como medidas corretivas para uma problemática gestada pelas circunstâncias desumanizantes, não identificadas como de responsabilidade do mesmo Estado nem mesmo do mercado, carecendo de ações compensatórias e solidárias a partir da teoria social do capital. A cargo dessa correlação entre investimentos em educação e políticas sociais, organismos multilaterais, como o Banco Mundial, atrelaram as correções de dívidas sociais históricas, como um novo paradigma, que, segundo sua previsão, favoreceria o desaparecimento dos bolsões de pobreza no mundo e a elevação da qualidade e inclusão social à escola em todos os seus âmbitos.

Lima (2009) destaca que ao longo de sua reorientação na década de 1990, a educação brasileira, na triangulação reestruturação produtiva, reforma do Estado e políticas educacionais, estava condicionada por uma projeção da qualidade de ensino, mas de maneira determinada pelos compromissos assumidos pelo Brasil como assignante do ideário neoliberal, frente às organizações multilaterais. As políticas educacionais para a educação básica geraram outro núcleo de preocupação: alunos excluídos dentro da própria escola, marcados por um acentuado analfabetismo funcional, havendo escola para poucos da Educação Básica ao ensino superior e o posicionamento equivocado de que estamos avançando sustentados pela teoria social do neoliberalismo.

O assentimento ao ideário neoliberal deflagrado no governo de Fernando Henrique Cardoso teve sua continuidade no governo de Luis Inácio Lula da Silva por meio da mesma orientação da revolução educacional gerenciada - a constituição de políticas educacionais paliativas à medida que se apresentam as tensões e reivindicações sociais. Sabemos que, historicamente, medidas paliativas não anulam ou erradicam injustiças sociais deflagradas, apenas desmobilizam ações, arrefecem direções e colocam em suspensão o caráter dos direitos fundamentais do homem como protagonista de seu processo sócio-histórico, mas não sem isenção, pois ao longo das proposições as diretrizes neoliberais se materializam em seu esteio.

Muito mais do que uma razão de atendimento social em si, as políticas educacionais consentidas e naturalizadas caracterizam-se como uma das faces da reorganização do metabolismo do capital, que certamente não se encerra com medidas pontuais em si ou pelo reconhecimento do estado de expropriação de direitos, mesmo porque a exclusão social e a exploração selvagem do trabalhador alcançam uma dimensão contraditória e difusa na estrutura de poder na relação explícito-implícito.

O explícito trata das interfaces oficiais das políticas e legislações para a sociedade sob os auspícios de horizontalização indistinta dos cidadãos. O implícito, o não dito, também pode ser considerado como currículo oculto que funciona 
como reafirmação da estrutura imobilista da teoria social capitalista que, em uma pele de cordeiro, não leva em conta qualquer possibilidade de romper com o lobo que traz no seu seio. Propõe-se justiça, mas não se rompe com a sua socialização em sentido amplo e universal, muito embora esse seja o discurso; legitima-se a universalização da educação básica, mas não se rompe com as desigualdades sociais e continuam a se registrar índices alarmantes de baixa qualidade do ensino no Brasil e no mundo, pois parte-se de um pressuposto contingenciado e utópico de equidade: legal, mas não de fato.

Nessa direção, a ideia de uma educação escolar para todos, no sentido literal, levando-se em conta o caso brasileiro, está longe de se constituir uma realidade concreta, o que é ainda muito pior quando se trata da oferta da educação superior para a classe desfavorecida economicamente. Em consonância com o sistema capitalista, qualquer ação política que se respalde na organização da teoria social do capitalismo, constituir-se-á num elemento paliativo e remediativo em que os grupos desfavorecidos continuarão nessa situação, uma vez que, como Kurz (1993, p.233 - colchetes nossos) afirma, trata-se de "[...] um sistema louco e perigoso para humanidade [que] não será abandonado voluntariamente por seus representantes [...]" a menos que haja um despertamento e mobilizações sociais significativas e suficientes para a reversão de sua estrutura.

\section{PARTICIPAÇÃO E DEMOCRACIA INDUZIDAS NA E PARA A ESCOLA NO BRASIL}

O movimento atual que rege a sociedade capitalista em termos econômico, social e político vem orientando a configuração da democracia no movimento educacional brasileiro, demonstrando que a participação, categoria imprescindível nessa configuração, nem sempre se sustenta em um princípio que inspire um compromisso social e político que venha a assegurar uma concepção de educação que conceba o homem como sujeito da história e não sujeitado a ela.

São paradoxais as evidências que demarcam nitidamente que o significado do princípio que vem regendo a participação na gestão democrática da educação não é o mesmo quando se faz a análise de situações ocorridas no Brasil nos anos finais da década de 1970 e anos iniciais da década de 1980 e as relaciona com situações ocorridas no pós-1988, em específico no decorrer da década de 1990 e, mais precisamente, nos anos iniciais do século XXI, tempo histórico deste estudo. Em vista disso, muitas evidências foram materializadas no pós-1988, marco da elaboração da Constituição Federal de 1988, com acento no início e decorrer da década de 1990, caracterizando outro momento com características visíveis do modelo econômico chamado de neoliberalismo.

Tais evidências podem ser assim resumidas: mudança na função do Estado em relação ao exercício das políticas públicas; ênfase nas reformas; a corrida pela busca da modernização administrativa e econômica; a descentralização, a defesa do consenso em substituição ao conflito; a busca de parcerias; a ênfase nas 


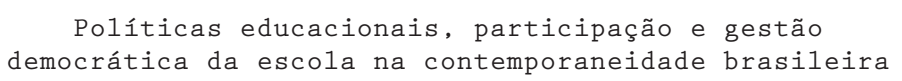

políticas de participação da sociedade civil, esta última com uma conotação cujo diferencial em termos do princípio fundamentador da participação de caráter popular articulado ao político se mostra nítido em relação aos acontecimentos dos anos finais de 1970 e anos iniciais da década de 1980.

Neves (2002) analisa a concepção de participação presente no espaço educacional no decorrer da década de 1990 destacando estar na mesma o ponto mais intrigante da política em voga, a sua contradição. O discurso é pautado na participação popular, mas na prática se percebe uma inibição da percepção dos sujeitos históricos quanto ao autoritarismo crônico atrelada à própria correlação de forças na busca do poder dentro das instituições, pontos que não deixam entrever limites impostos.

Essa análise, entre outras, anuncia que o significado do princípio da participação vem indicando que a democracia não tem conseguido se articular a uma concepção que legitime seus valores efetivos, e empiricamente é afirmado que a participação é reduzida, restrita, mínima, controlada, regulada, cooptada, suscitandose posicionamentos vários, dentre eles aqueles que apregoam que a participação da população não tem sentido, quando parece "[...] que tudo o que há de essencial e substantivo está previamente decidido" (DI GIORGI, 2004, p. 120).

A política educacional é aqui entendida como o conjunto de ações, programas, projetos, leis que movimentam a área educacional, sempre pautada numa determinada concepção de sociedade e de homem. Assim, cabe esclarecer que os conceitos sobre participação e política educacional precisam ser colocados de modo a esclarecer que o modo como se entende as duas categorias não é redutível ao discurso oficial.

Entende-se a participação como uma categoria histórica construída nas relações sociais, um princípio orientador de ações que precisam ser constantemente aprendidas e apreendidas de modo que o homem possa se constituir em sujeito da história, possa fazer a história, mesmo com a percepção de que nessa estrutura social as condições para esse fazer não lhe são dadas a priori, mas precisam ser conquistadas no movimento histórico presente nas relações sociais, políticas e econômicas, ou seja, possibilitadas pelas contradições e mediações presentes numa totalidade social, seguindo uma premissa que leva a Gramsci, que apresenta a seguinte opção quanto à participação:

[...] é preferível 'pensar' sem disto ter consciência crítica, de uma maneira desagregada e ocasional, isto é, 'participar' de uma concepção de mundo 'imposta' mecanicamente pelo ambiente exterior, ou seja, por um dos vários grupos sociais nos quais todos estão automaticamente envolvidos [...] ou é preferível elaborar a sua própria concepção de mundo de forma crítica, [...] escolher a própria esfera de atividade, participar ativamente na produção da história do mundo, ser o guia de si mesmo e não aceitar do exterior, passiva e servilmente, a marca da própria personalidade? (GRAMSCI, 1991, p.12).

Afirma-se que a participação vem sendo fundamentada em uma concep- 
ção de mundo imposta mecanicamente pelo ambiente exterior. Entretanto, o que se defende é a participação ativa na produção histórica do mundo. As possibilidades de se colocar isso em prática não são facilmente encontradas no seio desta sociedade, mas precisam ser buscadas continuamente nas contradições e nas mediações existentes no próprio seio dessa sociedade, segundo orientações gramscianas. Por isso, a participação é entendida como um princípio orientador de todas as ações, no caso, das ações que no seu conjunto dão corpo à política educacional, que é uma área específica da política social, distinta da democracia e participação induzidas em nome da gestão democrática que mais contribuiu para a conservação de aparências do que a sustentação de sua real essência.

A gestão democrática para ser legítima deve fazer valer a participação e democracia sem mascaramentos, isto é, considerados serão o ideário da consciência coletiva e suas solicitações quanto à leitura de mundo. É exatamente nesse sentido que é necessário analisá-la criticamente, problematizá-la, desmistificá-la, o que corresponde a transitar entre suas possibilidades e seus limites. É esse caráter de superação de uma potencialidade imutável da gestão democrática que poderá possibilitar uma forma consequente a um conteúdo de construção de processos democratizadores, que, de fato, correspondam à superação das condições autoritárias e autocráticas presentes, no início do século XXI, na gestão escolar, como observaremos a partir de uma caso concreto.

\section{GESTÃO DEMOCRÁTICA: OLHARES E LEITURAS DE MUNDO}

Por meio da tese da Curvatura da Vara, que Saviani (1983) toma emprestada de Lênin, comprova-se a necessidade de empreendermos um processo de ressignificação da gestão democrática. Diz Saviani (1983, p. 63) que

\footnotetext{
[...] assim como para se endireitar uma vara que se encontra torta não basta colocá-la na posição correta, mas, é necessário curvá-la do lado oposto, assim também, no embate ideológico não basta anunciar a concepção correta para que os desvios sejam corrigidos; é necessário abalar as certezas, desautorizar o senso comum. E para isso nada melhor do que demonstrar a falsidade daquilo que é tido como obviamente verdadeiro demonstrando ao mesmo tempo a verdade daquilo que é tido como obviamente falso.
}

A partir dessa ideia ou temos uma vara teimosa ou não curvarmos a vara o suficiente para que ela tomasse prumo. Ela, a vara, continua colada ao setor da hierarquização verticalizada. A democratização ainda depende basicamente da vontade daqueles que estão no Staff, no poder. Não há, portanto, um modelo participativo que consiga deslocar a gestão democrática do eixo da centralização para o eixo do coletivo.

Quem tem, portanto, a necessidade de implantar a gestão democrática: os órgãos centrais, os dirigentes escolares e/ou a comunidade escolar? 


\section{A TESE EM CONSTRUÇÃO}

Estas reflexões podem nos ajudar a desenvolver o nosso argumento sobre o que é a gestão democrática, o que temos e o que queremos a partir da manifestação de seus sujeitos envolvidos no processo.

Tais manifestações foram sistematizadas a partir de uma enquete com professores e diretores de escolas públicas estaduais e municipais e supervisores, assessores e analistas de educação da Superintendência Regional de Educação da Região do Alto Paranaíba, em Minas Gerais. Foram aplicados questionários contendo quatro questões básicas para que esses segmentos desenvolvessem em grupo suas discussões.

\section{0 que é a gestão democrática hoje?}

Os sujeitos participantes da enquete não têm dúvidas quanto aos elementos instrumentalizadores da gestão democrática escolar: CE, ED e PPP (Conselho de Escola, Educação Democrática, Projeto Político-Pedagógico), tornando-se bastante comum e aceitável a legalidade dos canais legítimos de participação, bem como a naturalização de sua obrigatoriedade.

Um grupo de educadores (GE) da instituição A (GE-A) afirma que todos os "projetos exigem a participação de professores, pais e alunos na tomada de decisões, através dos colegiados escolares. Esta participação é imposta através de legislação que define a forma desta participação" (GE-A).

Outro grupo aponta que a "gestão democrática do ensino e da escola assegura o direito de todos à educação, fortalece a escola como instituição plural, sem preconceitos e contribui para a redução das desigualdades sociais, culturais e étnicas". (GE-D). Isso aponta para um caráter redentor e panaceico da gestão democrática.

Outros grupos divergem dessa tendência. Segundo o GE-E, "há muito que se trilhar em direção a uma real incorporação ao processo democrático.”. Essa fala demonstra o ceticismo que muitos têm em relação ao ideal da gestão democrática, tese que é defendida também pelo grupo GE-F, “A participação na gestão democrática configura-se em um engenhoso instrumento de colaboração e fortalecimento do estado em relação a educação formal.’.

Contundente, nessa perspectiva de gestão conivente com o projeto do capital, é o GE-G, ao afirmar que a "gestão democrática hoje, está voltada com ações na verdade reprodutoras de uma sociedade infelizmente alienada e passiva, ditando regras e não estabelecendo uma relação de diálogo ideal com os envolvidos, estabelecendo meramente uma transmissão de ordens, alegando, na maioria das vezes cumprirem determinações que lhes vêm de cima, não proporcionando, assim, momentos para discussão.”.

Isso é referendado por outro grupo, ao afirmar que “essa concepção de diretor como gestor/gerente escolar continua a manter a separação fundamental 
entre os que mandam e os que fazem, pois o torna como o funcionário responsável pela administração, e não com a parte pedagógica. [...] A importância atribuída ao diretor pode ser até certo ponto contraditória ao processo de democratização, mas temos que ter consciência de que eles são os principais agentes a se envolver como sujeitos capazes de pensar e gerir a escola pública.” (GE-J).

Para o GE-I, a prática da gestão democrática "não foi conquistada pelos segmentos da escola, o que significa que para isso deve-se romper com o modelo tradicional de administração escolar e do modelo tradicional de participação, existindo ainda hoje a dominação e autoritarismo imposto pelo poder."

A partir da exposição das ideias anteriores podemos destacar que os canais legítimos de participação tem sido implementados na perspectiva da obrigatoriedade., o que irá fazer com que eles tenham um caráter pro forma.

\section{Para você o que deveria ser a gestão democrática?}

Os sujeitos da pesquisa indicam que a gestão democrática é, em síntese, a articulação de todos. Entretanto, referenda um grupo de educadores (B), "isso não acontece com a maioria dos profissionais envolvidos no processo. Sempre há alguém que está sempre discordando das ideias, tornando tudo mais difícil, não havendo senso comum para se chegar a um objetivo desejado e concreto".

A gestão democrática deveria ser o exercício de funções que "fortaleçam a presença e atuação das pessoas envolvidas" em processos educativos (GE-D). Essa fala indica uma possibilidade de participação nas decisões substanciais da escola. Diferentemente, a fala do GE-F indica uma participação instrumental. Para esse grupo, a gestão democrática deveria "buscar maior atuação dos setores organizados de nossa sociedade na manutenção da escola.”

Temos, portanto, duas posições distintas, uma que indica a necessidade de todos articuladamente em torno do projeto da escola, mas que esbarra no individualismo de cada sujeito, e outra posição que aponta a operacionalidade dessa união: a manutenção da escola.

\section{Como tem sido implementada a gestão democrática na instituição na qual você trabalha?}

É consenso, entre os educadores, que a gestão democrática é sempre um processo lento. Essa ideia é referenciada, por exemplo, na fala do GE-E: "O processo de gestão democrática em nossa instituição não é diferente, caminha a passos lentos com tentativas e muitas falhas. O exercício da democracia e de participação nas instituições é o reflexo da sociedade: uma distância entre o discurso e a prática".

Para os educadores do GE-F, a gestão democrática em sua escola sofre um processo de ruptura. Anteriormente a escola era gerida por um professor de orientação tradicional, severo e centralizador no trato com os alunos e disciplinas. Isso foi rompido quando um "professor jovem, vindo de uma grande cidade (...) 


\section{Políticas educacionais, participação e gestão \\ democrática da escola na contemporaneidade brasileira}

fincou raízes em nossa cidade e deu início a uma nova era na educação (...). A linha dura, austera, deu lugar a uma nova realidade, em que já se podia opinar e até se manifestar". Entretanto, é um processo que depende sempre de uma liderança, um condutor, um administrador.

Isso significa que os processos de gestão democrática implementados até o início do século XXI não romperam com o modelo autocrático de gestão. Afinal, mesmo "a escola possuindo colegiado, APM, processo de escolha de diretor, ainda deparamos com entraves dos órgãos superiores que ainda concentram o poder de decisão, o que dificulta a autonomia da instituição em colocar em prática os objetivos e metas do PPP" (GE - G).

O modelo burocrático, subsidiado pela hierarquização de poder de mando e obediência, ainda predomina nas escolas. Para o GE-I, "na instituição em que trabalhamos a gestão democrática ainda não conta com a participação dos servidores na tomada de decisões, não há momentos de discussão e reflexão sobre o desempenho da instituição. Não há preocupação com o nível de participação dos servidores. Na maioria das vezes, as informações em benefício dos servidores que deveriam se divulgadas amplamente, restringem-se a uns poucos".

O que podemos destacar é morosidade da construção da gestão democrática. Afinal ela é um processo. Entretanto, conforme afirmam os educadores pesquisados, a participação tem esbarrado em vários entraves, dentre eles o processo centralizador das tomadas de decisões, seja na perspectiva do diretor centralizador, seja na perspectiva do diretor condutor da participação.

\section{Quais são os elementos que definem a gestão escolar como gestão demo- crática?}

Para os educadores que responderam à enquete, a gestão democrática se fundamenta em preceitos coletivos, participativos e políticos. "Somente com ações coletivas a comunidade se organiza para cobrar dos poderes públicos a manutenção da escola" (GE-A).

Destaque-se o trecho como algo que representa um ato revolucionário: cobrar a manutenção da escola!

Os mesmos educadores registram o seguinte: "Constituindo fundamentalmente a busca de autonomia, ajudas financeiras, angariando recursos, firmando parcerias e compromissos de mútua ajuda.".

A ideia de gestão democrática oscila entre a sua operacionalidade instrumental, na qual os participantes devem buscar contribuir com a manutenção da escola e entre um modelo solidário, no qual a "gestão democrática implica participação intensa e constante dos diferentes segmentos sociais nos processos decisórios no compartilhar as responsabilidades, uma articulação de interesses, na transparência das ações em mobilizações e compromisso social, em controle coletivo" $(\mathrm{GE}-\mathrm{E})$.

Entretanto, as razões mobilizadoras da gestão democrática são situações

Rev. Ensaio | Belo Horizonte | v. 14 | n. 01 | p.51-64 | jan-abr | 2012 
minimizadas, cuja potencialidade é muito diminuta.'Tem-se buscado uma participação efetiva, onde são coletadas opiniões para o planejamento, implementação e avaliação das atividades" (GE-C). A participação aqui tem uma dimensão que fica entre a informação e a deliberação, ou seja, é uma consulta. Esse é um dos níveis menos intenso de participação. O nível consultivo indica mera informação, o que estabelece uma relação consensual e submitiva entre os membros e os dirigentes de uma organização.

\section{CONSIDERAÇÕES FINAIS}

Tanto no governo FHC quanto no governo Lula fora planificada a acomodação das políticas de desenvolvimento nacional ao sistema capitalista constituído, agregando-se, a partir de seus condicionantes, os elementos orientadores para resolução dos problemas sociais por meio de políticas educacionais de inclusão social, que passam a constar como ponto presencial recorrente, principalmente na gestão Lula. Percebemos que havia o condicionamento do papel do Estado pela iniciativa privada e os organismos multilaterais na defesa e consecução de políticas educacionais que limitavam as mudanças necessárias para uma escola não excludente no Brasil.

A luta de uma escola para todos no Brasil ainda é uma aspiração. Entendemos que quando a imobilização social se justifica por concessões e rearranjos históricos, há que levantar vozes em seu despertamento, porque a justiça social e os processos de não exclusão não são resultantes de medidas outorgadas, mas de conquistas. Por meio de uma contrainternalização provocada pela educação, por meio da emancipação concreta da sociedade e do homem, poderemos reunir a dimensão necessária de emancipação, libertação, justiça social, humanização e universalização das construções sociais, rompendo definitivamente com o ordenamento da teoria do sociometabolismo do capital, na atualidade, sob a denominação de neoliberalismo.

A trilogia Estado, políticas educacionais e escola no Brasil ao longo do tempo tem se constituído como um marco regulador e reforçador da educação dualista, delimitada pela divisão social de classes, incentivando em maior ou menor grau a indução à participação e gestão democrática correlatas ao seu ideário.

Defende-se que a solidariedade entre os povos e a comunhão dos benefícios da humanidade fazem parte de uma realidade objetiva e, portanto, envitando esforços a partir das necessidades objetivas, incluindo-se o acesso aos níveis mais elevados da educação, assim, no projeto de sociedade atual, conseguir-se-á um concluir da superação das desigualdades sociais. Entretanto, alertam Adorno \& Horkheimer (1985, p.48) que

Os próprios dominadores não acreditam em nenhuma necessidade objetiva, mesmo que às vezes deem esses nomes às suas maquinações. Eles se arvoram em engenheiros da história universal. Só os dominados aceitam como necessidade intangível o processo que, a cada decreto elevando o nível da vida, aumenta o grau de sua impotência." 


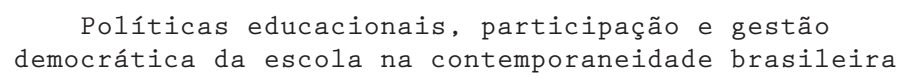

A aceitação do sociometabolismo do capital permanente e universal, condicionada por ideologismos reiterados ascendem a um âmbito cada vez maior, ao ponto de os movimentos sociais e a sociedade como um todo chegarem à conclusão de que

É bem mais fácil resignar-se à irreversibilidade do dilema afirmada no determinismo cego deste slogan político de nosso tempo - sem sequer tentar uma avaliação, muito menos um questionamento, de suas serí́ssimas implicações - do que imaginar a forma de enfrentá-lo. (MÉSZÁROS, 2006, p.37).

Qual seria a alternativa contraposta a essa proposição?

O caminho para a emancipação do Estado, das políticas educacionais na proposição e materialização de uma escola e oportunidades educacionais, inclusive na universidade, centra-se no rompimento com a lógica capitalista e na universalização da educação e trabalho como atividade humana auto-realizadora. Nesse encaminhamento concluímos com Mészáros (2005, p.27) que limitar "[...] uma mudança educacional radical às margens corretivas interesseiras do capital significa abandonar de uma só vez, conscientemente ou não, o objetivo de uma transformação social qualitativa". De forma correlata, a gestão democrática não é nada daquilo que pressupõe uma idealização progressiva de autonomia e poder decisório à luz que induz o sociometabolismo do capital. O que temos concretamente não tem sido uma prática emancipatória, mas uma centralização de decisões substantivas, enquanto o supérfluo fica para ser decididopelo que aprendemos a chamar de comunidade escolar.

Essa nomenclatura representa outro equivoco, pois os pais, responsáveis por alunos, alunos, professores, supervisores, orientadores, inspetores escolar, diretores, vice-diretores, bedéis, cozinheiras, serventes, e outros mais, não têm identidade coletiva, mas necessidades diferencias. Portanto, não formam uma comunidade, formam grupos distintos, que se organizam um mínimo necessário para sobreviver na organização escolar. Gerir democraticamente uma escola é muito mais do que fiscalizar a escola, contribuir financeiramente, cuidar de alunos no intervalo, ajudar na feitoria da merenda, ajudar a pintar, varrer, cuidar da escola: é buscar e materializar o sentido de consciência coletiva. A educação emancipatória não tolhe, não cerceia nem induz a adesão aos interesses particularistas; antes liberta e apresenta de forma recorrente as razões pelas quais os instrumentos legítimos de participação e democracia devem ser problematizados, quando da ameaça de sua secundarização nos processos sócio-históricos. 
Paulo Gomes Lima | Maria Alice de Miranda Aranda

Antonio Bosco de Lima

\section{BIBLIOGRAFIA}

ADORNO, T.W. \& HORKHEIMER, M. Dialética do esclarecimento. Rio de Janeiro: Jorge Zahar Editor, 1985.

DI GIORGI, Cristiano. Uma outra escola é possivel: uma análise radical da inserção social e da democracia na escola do mundo globalizado. Campinas, SP: Mercado de Letras, 2004. FREITAS, Luis Carlos de. A avaliação e as reformas dos anos de 1990: novas formas de exclusão velhas formas de subordinação. Educ. Soc., Campinas, vol. 25, n. 86, p. 133-170, abril 2004.

GRAMSCI, Antonio. Os intelectuais e a organização da cultura. (Trad.) Carlos Nelson Coutinho. Rio de Janeiro, RJ: Civilização Brasileira, 1991.

KURZ, Robert. O colapso da modernização. São Paulo: Paz e Terra, 1993.

LIMA, Paulo Gomes. Ações afirmativas como eixo de inclusão de classes sociais menos favorecidas à universidade brasileira: um terceiro olhar entre pontos e contrapontos. 2009.178 f. Relatório Final de Pesquisa (Pós - Doutoramento) - Departamento de Filosofia e História da Educação, da Faculdade de Educação da Universidade de Campinas, Campinas, SP, UNICAMP, 2009.

MÉSZÁROS, Istvan. A educaşão para além do capital. São Paulo: Boitempo Editorial, 2005. MÉSZÁROS, Istvan. Para além do capital. São Paulo: Boitempo Editorial, 2006.

NEVES, Lúcia Maria Wanderley. As massas trabalhadoras começam a participar do banquete, mas o cardápio é escolhido à sua revelia, ou democracia e educação escolar nos anos iniciais do século XXI. In: FÁVERO, Osmar; SEMERARO, Giovanni (Orgs.). Democracia e Construção do Público no Pensamento Educacional Brasileiro. Petrópolis, RJ: Vozes, 2002. SANFELICE, José Luis. Prefácio. In: SILVA, Maria Abádia da. Intervenção e consentimento: a política educacional do Banco Mundial. São Paulo: Autores Associados, 2002.

SAVIANI, D. Escola e democracia: teorias da educação, curvatura da vara, onze teses sobre educação e política. São Paulo, Cortez Autores Associados, 1983.

SILVA, Maria Abádia da. Intervenção e consentimento: a política educacional do Banco Mundial. São Paulo: Autores Associados, 2002.

Data de recebimento: $31 / 07 / 2010$

Data de aprovação: 11/09/2011

Data da versão final: 01/12/2011 